\title{
Transferências Voluntárias da União para os Municípios Brasileiros: Uma Análise da Execução dos Recursos nas Políticas do Setor de Resíduos Sólidos
}

Voluntary Transfers from the Union to Brazilian Municipalities: analysis of execution of resources in policies for the sector of solid waste

Voluntarias de la Unión para los ayuntamientos brasileños: Un análisis de la ejecución de los recursos en las políticas del sector de residuos sólidos

Fernanda Pinheiro Pantoja

Mestrado em Gestão Pública - Universidade Federal do Pará. Analista de Planejamento e Gestão/Instituto Brasileiro de Geografia e Estatística http://lattes.cnpq.br/9219050519665060 https://orcid.org/0000-0001-6208-1035 nanda_fiscal@hotmail.com

José Almir Rodrigues Pereira Doutorado em Hidráulica e Saneamento - Universidade de São Paulo - Escola de Engenharia de São Carlos Professor Titular do Instituto de Tecnologia - Universidade Federal do Pará http://lattes.cnpq.br/9918600634569244 https://orcid.org/ 0000-0002-3144-1787 rpereira@ufpa.br

Resumo: O objetivo deste artigo é analisar a execução dos recursos de Transferências Voluntárias da União para os municípios brasileiros nas políticas públicas do Setor de Resíduos Sólidos, tendo como objeto de investigação o programa temático específico do Plano Plurianual (PPA) Federal 2012-2015. Na pesquisa realizada, foram levantadas informações orçamentárias e financeiras nos bancos de dados do Ministério do Planejamento, da Controladoria Geral da União e do Senado Federal. Os resultados encontrados com base na análise comparativa entre recursos executados e autorizados na vigência do PPA apontam que, apesar do apoio financeiro prestado pelo governo federal, a alocação desse auxílio não tem se efetivado na esfera municipal. A situação decorre da conjugação de fatores - condicionantes políticas e técnicas - que repercutem de forma negativa na aplicação desses repasses e acabam por contribuir para o não cumprimento da Lei da Política Nacional de Resíduos Sólidos, Lei no $12.305 / 2010$

Palavras-chave: Municípios, Resíduos Sólidos, Transferências Voluntárias Federais.
Abstract: This work aims to analyze the administration of Voluntary Transfers from the Union (Brazilian Federal Entity) resources to Brazilian Municipalities in public policies for the Sector of Solid Waste. The object of investigation is a specific thematic program of 2012-2015 Federal Pluriannual Plan (PPA - Programa Plurianual). Budgetary and financial information was obtained from the Ministry of Planning, the General Comptroller of the Union, and Federal Senate database. The results found from comparative analysis between executed and authorized resources in PPA validity indicate that, despite financial support by Federal Government, the allocation of such resources have not been implemented in municipal sphere. This situation derives from some conjugated factors - political and technical constraints, which reflect negatively on these resources application and contribute to non-compliance with the Law of National Policy of Solid Waste, Law No. 12.305/2010.

Keywords: Municipalities, Solid Waste, Federal Voluntary Transfers.
Resumen: El objetivo de este artículo es analizar la ejecución de los recursos de transferencias voluntarias de la unión para los ayuntamientos brasileños en las políticas públicas del departamento de residuos sólidos, teniendo como objeto de investigación el programa temático específico del plan plurianual (PPA) federal 2012-2015. En la búsqueda realizada, fueron alzadas informaciones de presupuestos $y$ financieras en los bancos de datos en el ministerio de planificación y contraloría general de la unión y del senado federal. Los resultados encontrados con base en el análisis comparativa entre recursos ejecutados y autorizados en la vigencia de PPA muestran que mismo con el apoyo financiero prestado por el gobierno federal la asignación de este subsidio no viene efectuándose en el campo municipal. La situación transcurre de la conjunción de factores condicionantes políticos y técnicos que reflejan de forma negativa en la aplicación de estos recursos y que por fin acaban contribuyendo para el no cumplimiento de la ley de política nacional de residuos sólidos, ley $n^{\circ}$ 12.305/2010.

Palabras Clave: Municipios, Residuos Sólidos, Transferencias Voluntarias Federales.

Texto completo em português: http://www.apgs.ufv.br

Full text in Portuguese: http://www.apgs.ufv.b

\section{Introdução}

A necessidade de ações planejadas e coordenadas para minimizar os impactos na degradação do meio ambiente e, consequentemente, melhorar a qualidade de vida da população, coloca em pauta a gestão de resíduos sólidos no Brasil. É preciso observar que o crescimento demográfico contínuo no país, associado ao aumento do consumo de produtos industrializados, tem evidenciado o desafio de manejo e controle dos materiais descartados a partir da implantação de alternativas técnicas apropriadas, socialmente justas e ambientalmente adequadas (Philipi \& Aguiar, 2005; Martins, 2013).

Em que pese o destaque que o tema tenha ganhado recentemente no cenário brasileiro, há décadas, é causa de preocupação no contexto internacional. $\mathrm{Na}$ perspectiva do desenvolvimento sustentável, não há como pensar em qualidade de vida sem pensar na qualidade do meio ambiente, pois uma está condicionada à outra (Buarque, 2002). Dessa forma, o tratamento da temática contempla uma visão macro, que envolve aspectos 
econômicos, sociais, ambientais, políticos e culturais (Magalhães, 1998).

Apesar do consenso sobre a necessidade de realização de ações efetivas na gestão de todas as etapas do sistema de resíduos sólidos que, segundo Massukado (2004), vai da geração até a disposição final, o posicionamento do governo brasileiro teve lenta evolução na normatização específica do setor. Essa ausência de regulamentação foi, por muito tempo, utilizada para justificar a falta de estrutura nos municípios brasileiros, haja vista que a lacuna legal enfraqueceu a definição de responsabilidades, o planejamento de ações e os investimentos no setor (Heller, 2005; Costa, 2010).

Na tentativa de modificar esse cenário, o Poder Público, ainda que de forma retardatária, dada a complexidade do tema, vem procurando complementar seus instrumentos legais, com vistas à formulação de um arcabouço jurídico institucional capaz de fomentar melhorias no sistema, sendo que, na Constituição Federal de 1988, foi inserida a contribuição obrigatória dos entes para o avanço das condições de saneamento básico, assim como, para a proteção do meio ambiente, de forma conjunta e articulada (Paiva, 2012). Posteriormente foram editadas a Lei no 11.445 (2007), que trata da Política Nacional de Saneamento Básico (PNSB), e a Lei no 12.305 (2010), que regulamenta a Política Nacional de Resíduos Sólidos (PNRS).

Dessa forma, considerando a segurança legal e a intenção de enfrentar os desafios inerentes ao tema por meio das políticas públicas, no último Plano Plurianual (PPA) da União, quadriênio 2012-2015, instituído pela Lei no 12.593(2012), foi definido o Programa Temático Resíduos Sólidos, supervisionado pelo Ministério do Meio Ambiente (MMA), órgão responsável pela coordenação da elaboração e da implementação do Plano Nacional do Setor.

As ações específicas desse programa foram relacionadas a ampliação de acesso aos serviços de manejo ambientalmente adequados, a indução da gestão consorciada dos serviços e a inclusão de catadores de materiais recicláveis (Brasil, 2012). O montante de recursos da União definido para essas atividades no período de 2012 a 2015, foi na ordem de aproximadamente 530 milhões de reais, contemplando a aplicação descentralizada de parcela desses recursos aos municípios, por meio do Instituto das Transferências Voluntárias, também conhecidas como Transferências Discricionárias ou Negociadas (Arretche, 2012; Melo \& Soares, 2016).

A previsão de repasse de recursos do Orçamento Geral da União aos municípios representa, na concepção do federalismo fiscal brasileiro, a possibilidade de auxílio financeiro complementar e necessário para as ações das políticas públicas do setor, especialmente pela ampliação da responsabilidade das prefeituras, estabelecida na Lei no 12.305 (2010), às quais, além de responderem pela limpeza urbana, pela coleta e pela destinação final dos resíduos, também passaram a ser responsáveis pelo encerramento dos lixões, dispondo de prazo determinado para isso (Brasil, 2010).

Nesse contexto, dadas as exigências da Política Nacional de Resíduos Sólidos e à luz da bibliografia acerca da temática "transferências fiscais de recursos", o objetivo deste artigo consiste em analisar as transferências voluntárias da União aos municípios, na vigência do PPA 2012-2015, especificamente em relação à operacionalização da execução orçamentária e financeira do Programa Temático Resíduos Sólidos, elucidando fatores intervenientes no processo.

Além desta introdução e das considerações finais, o artigo está estruturado em cinco seções. Na primeira, são apresentados os procedimentos metodológicos utilizados na condução do estudo. $\mathrm{Na}$ segunda, são abordados os aspectos normativos e institucionais do Setor de Resíduos Sólidos. Posteriormente, na terceira seção, são feitas considerações acerca das necessidades de investimentos. Em seguida, na quarta seção, é abordado o PPA/federal 2012-2015 e as transferências voluntárias.

Por fim, na quinta seção, são apresentados os resultados do programa em consonância com a bibliografia utilizada, retratando as contribuições do estudo e trazendo reflexões acerca do uso das transferências fiscais de recursos (voluntárias) no financiamento das políticas do setor no período pós-regulamentação, evidenciando a necessidade de buscar mecanismos, que induzam a colaboração entre os entes federativos e as boas práticas na gestão desses recursos. Aponta também, novas perspectivas de estudos, tanto em âmbito nacional quanto em nível regional, no que tange ao tratamento da temática e a sua inserção no processo de planejamento das instâncias governamentais, diante das demandas da sociedade, cada vez maiores, por melhorias na qualidade do meio ambiente.

\section{Procedimentos Metodológicos}

No que se refere aos objetivos propostos, esta pesquisa é classificada como exploratória e descritiva (Gil, 2002), pois, além de proporcionar maior familiaridade com o problema, traz como eixo central a preocupação em observar os fatos, registrá-los, analisálos e interpretá-los, sem a interferência nem manipulação do pesquisador (Triviños, 1987). Quanto aos procedimentos técnicos relacionados a coleta de dados, foi utilizada a pesquisa documental e bibliográfica. De acordo com Gil (2002), aquela apresenta algumas vantagens por ser "fonte rica e estável de dados", não implica altos custos, não exige contato com os sujeitos da pesquisa e possibilita uma leitura aprofundada das fontes. Ela é semelhante à esta, segundo o autor, e o que as diferencia é a natureza das fontes, sendo um material que ainda não recebeu tratamento analítico ou que ainda pode ser reelaborado, de acordo com os objetivos da pesquisa.

Como fonte primária de informações, foram utilizados dados oficiais publicados pelo governo federal, como os disponíveis no Portal da Transparência (CGU, 2012), no Portal dos ConvêniosSICONV (MPOG, 2015) e no Portal Orçamento do Senado Federal - Sistema Siga Brasil (Senado Federal, 2015). A definição do período para a realização do estudo considerou a vigência do PPA/federal 2012-2015, que correspondeu ao primeiro PPA editado sob a vigência da Lei no 12.305 (2010).

A partir da seleção do Programa Temático Resíduos Sólidos, código 2067, buscou-se nas Leis Orçamentárias Anuais, aprovadas 
pelo Congresso Nacional, o montante de recursos autorizados e destinados à modalidade transferências aos municípios (CGU, 2012). Uma vez localizadas e coletadas as informações nas bases de dados governamentais, o passo seguinte consistiu em agrupálas, observando no ciclo de realização da despesa pública, o volume de recursos executados, ou seja, efetivamente descentralizados (pagos) aos entes municipais nos exercícios financeiros delimitados na pesquisa.

Paralelamente, com base nos dispositivos legais que tratam do assunto, sobretudo os contidos nas Leis de Diretrizes Orçamentárias do período analisado, na Portaria Interministerial 507 (2011), na Lei oo 12.305 (2010), nos editais de chamadas públicas divulgados no Portal de Convênios e nos trabalhos acadêmicos que tratam da temática (Gomes, 2010; Martins, 2010; Soares, 2011, Andrade \& Castro, 2013), procurou-se identificar de que forma os requisitos exigidos na fase que antecede a assinatura dos instrumentos de pactuação influenciaram na efetivação do processo de descentralização, possibilitando a análise e a interpretação dos dados, o que, para Gil (2002), representa o cotejo com as teorias selecionadas para a fundamentação do trabalho. $\mathrm{A}$ discussão dos resultados levou em consideração os dados à luz das principais teorias que sustentam o estudo.

\section{Fundamentos Teóricos}

\section{Aspectos normativos e institucionais do Setor de Resíduos Sólidos no Brasil}

As definições para a expressão "resíduos sólidos" são várias na literatura relacionada ao tema, sendo algumas mais elaboradas que outras. Na linguagem corrente, o termo é concebido praticamente como sinônimo de lixo, mas, para Carvalho e Oliveira (2011), a utilização desta expressão é menos apropriada, uma vez que esta dá ideia de material sujo e sem serventia, sem reaproveitamento, enquanto aquela se refere a algo que tem valor econômico e utilidade para alguém.

O manejo incorreto de resíduos sólidos no Brasil tem reveladose como um dos fatores de maior impacto ambiental. Quando dispostos de forma inadequada, estes podem causar a poluição da água, do ar e do solo, além de criar um ambiente propício para a proliferação de macro e microvetores causadores de doenças (Jacobi \& Besen, 2011). Essa situação põe em risco a saúde da população, razão suficiente para alertar o interesse coletivo sobre a necessidade de políticas públicas que busquem reverter esse quadro (Garcia \& Flores, 2010; Paiva, 2012).

A partir da década de 90 , foi registrada uma sucessão de normativos legais que passaram a tratar das questões ambientais no cenário brasileiro, a começar pela Constituição Federal de 1988, que estabeleceu, no art. 24, que compete à União, aos Estados, ao Distrito Federal e aos Municípios legislar sobre a proteção do meio ambiente e a conservação da natureza. Ela também atribuiu competência comum aos entes federativos para tratar de saneamento básico (art. 23, IX), enquadrando a prestação dos serviços como de interesse local, sob a responsabilidade dos Municípios (art. 30, V), e inseriu na jurisdição dos Estados a incumbência para tratar de assuntos de interesse comum, no âmbito das regiões metropolitanas, das microrregiões e dos aglomerados urbanos, mediante a edição de Lei Complementar, para integrar a organização, o planejamento e a execução de funções públicas (art. 25, §3\%).

Adicionalmente, no art. 225, que trata exclusivamente sobre o meio ambiente, é prevista a garantia de um ecossistema ecologicamente equilibrado, ressaltando ser ele de uso comum do povo e essencial à qualidade de vida sadia, impondo-se ao Poder Público e à coletividade o dever de defendê-lo e preservá-lo para a presente e futura gerações (Magalhães, 1998; Buarque, 2002).

Posteriormente, na Política de Saneamento Básico, regulamentada pela Lei $n$ ㅇ 11.445 (2007), foram estabelecidas diretrizes para o setor, como a obrigatoriedade de planejamento, regulação, fiscalização das atividades e controle social. Nessa lei, é priorizada a sustentabilidade dos serviços e, estimulada a cooperação entre os entes federados, que deve ser orientada pelos princípios básicos da universalidade, da integralidade e da equidade, sempre privilegiando o interesse público.

No caso específico dos Resíduos Sólidos, a aprovação da PNRS, por meio da Lei no 12.305 (2010), regimentada pelo Decreto no 7.404 (2010), inicia a articulação institucional do setor envolvendo os entes federados, o setor produtivo e a sociedade em geral, na busca de soluções para os problemas gerados pela disposição e descarte inadequados do "lixo".

É oportuno destacar que, para o controle das ações em resíduos sólidos, é relevante observar as diversas etapas da estrutura que vão da geração até a disposição final. Aquela, no início da cadeia, tem significativo impacto no sistema, pois quanto mais resíduos produzidos, maiores serão os volumes a serem coletados, transportados, tratados e dispostos no meio ambiente (Massukado, 2004; Alcântara, Silva \& Pereira, 2016).

Em vista disso, nesse novo modelo é estabelecida a análise do ciclo de vida que avalia os impactos ambientais de determinado produto, desde a extração da matéria-prima até o retorno do resíduo final ao meio ambiente, a logística reversa, caracterizada por um conjunto de ações destinadas a viabilizar a coleta e a restituição dos produtos descartados ao setor empresarial para aproveitamento e/ou destinação adequada e a coleta seletiva dos materiais, previamente segregados, conforme sua constituição ou composição (Brasil, 2010).

Da mesma forma, a lei hierarquiza a prioridade a ser observada na gestão e no gerenciamento dos resíduos, qual seja: não geração, redução da quantidade e do volume processados, reutilização, reciclagem, tratamento e disposição final dos rejeitos. Estes são concebidos como sedimentos que, depois de esgotadas todas as possibilidades de tratamento e recuperação por processos tecnológicos disponíveis e economicamente viáveis, não apresentam outra possibilidade que não a disposição final ambientalmente adequada (Brasil, 2010).

A visão sistêmica sobre a gestão de resíduos é destacada entre os princípios da PNRS, que reconhece a necessidade de integração dos aspectos ambientais, sociais, culturais, econômicos, 
tecnológicos e da saúde pública (Magalhães, 1998; Buarque, 2002). Para Logarezzi (2004), as ações relacionadas ao segmento devem ser pensadas e trabalhadas como um todo, de modo abrangente, em longo prazo, e pelas três esferas - Federal, Estadual e Municipal.

Sob essa ótica, da parte para o todo, o marco regulatório insculpido na Política Nacional foi favorável à adoção de instrumentos de cooperação federativa e de gestão associada dos serviços públicos, criando oportunidades para o estabelecimento de parcerias, visando à convergência dos interesses de preservação ambiental (Heller, 2005; Costa, 2010).

Os instrumentos de planejamento do setor, por meio da instituição dos Planos de Resíduos Sólidos, também estão entre os principais mecanismos disciplinados pela referida lei, no caso os Planos Nacional, Estadual e Municipal. Ao Poder Público local Distrito Federal e municípios - compete à gestão integrada dos resíduos gerados em seus respectivos territórios (Brasil, 2010).

A elaboração de planos para os entes subnacionais é condição necessária para obtenção de recursos controlados pela União. E mais, os municípios que optarem por soluções consorciadas, bem como os que implantarem a coleta seletiva com a participação dos catadores de materiais reutilizáveis e recicláveis, terão prioridade no acesso a esses recursos (Brasil, 2010).

Apesar do avanço institucional, especialmente no que tange ao aparato normativo delineado, as profundas desigualdades regionais existentes na infraestrutura de saneamento básico, fazem da universalização e da melhoria dos serviços relacionados a limpeza urbana e ao manejo de resíduos sólidos um objetivo a ser alcançado e conquistado pelo Estado e pela sociedade brasileira.

De acordo com a Associação Brasileira de Empresas de Limpeza Pública e Resíduos Especiais (ABRELPE) (2014), que, anualmente apresenta o panorama da gestão de resíduos no Brasil, foram gerados $201.058 \mathrm{mil}$ ton/dia de lixo urbano em 2012, perfazendo uma produção média maior que $1 \mathrm{~kg} / \mathrm{hab}$./dia. Vale observar que essa geração aumentou 4,1\% em um ano, passando em 2013 para 209.280 mil ton/dia. É oportuno ressaltar que esse valor foi superior ao da taxa de crescimento populacional de 3,7\% registrada no período.

Em relação ao volume coletado, dados do Sistema Nacional de Informação sobre Saneamento (SNIS) (2013) demonstram que cerca de $91,30 \%$ e $91,10 \%$ da população foi atendida com coleta regular de resíduos sólidos em 2012 e 2013, respectivamente. No entanto, ainda é pouco expressiva a coleta seletiva, que, de acordo com esse sistema de informação governamental, não ultrapassou $36,50 \%$ nos dois anos analisados (SNIS, 2012).

A grande diferença entre as coletas regular e seletiva resulta em maior volume de materiais que precisam ser acondicionados, coletados e transportados para as unidades de destinação final de Resíduos Sólidos Urbanos (RSU) no País. Vale citar que, em muitos municípios brasileiros, existem somente lixões a céu aberto para o recebimento desses resíduos. Na Figura 1, é possível verificar que os índices de destinação final adequada dos RSU foram incipientes no País, passando de 57,98\%, em 2012, para 58,26\%, em 2013.

Figura 1. Destinação final dos Resíduos Sólidos Urbanos coletados no Brasil.
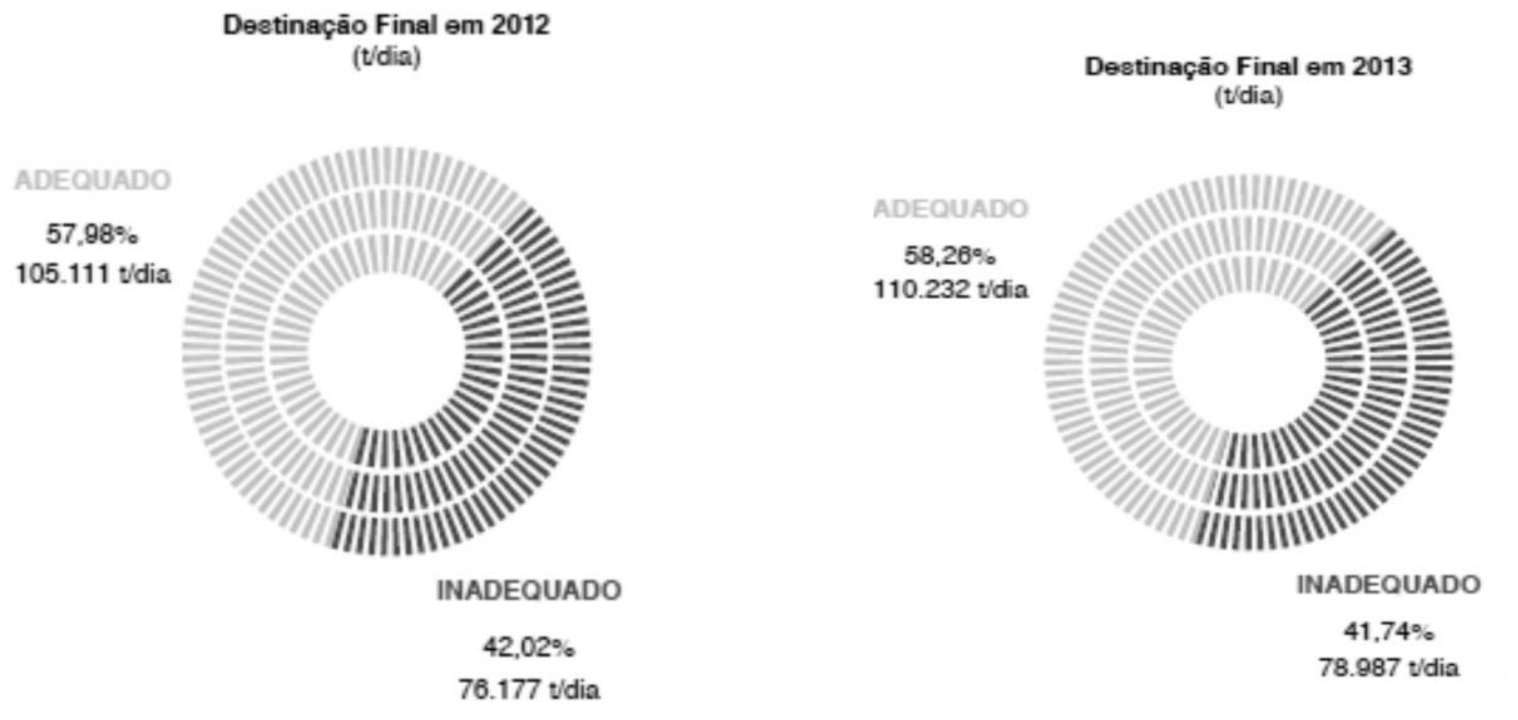

Fonte: Associação Brasileira de Limpeza Pública (ABRELPE). (2014). Panorama dos Resíduos Sólidos no Brasil. Recuperado de www.abrelpe.org.br.

Diante de tal panorama e alicerçada nos dados estatísticos, verifica-se que a realidade brasileira, no tocante ao tratamento e à disposição final de resíduos sólidos, representa um dos graves problemas que afetam a sociedade, tal como afirmado por Martins (2006, p. 88): como um dos itens que constituem o serviço de saneamento básico, a coleta e disposição adequadas dos resíduos sólidos correspondem modernamente a um dos maiores dilemas das grandes cidades, apresentando facetas sócio ambientais, econômicas e políticas.

Essas três facetas representam as dimensões da sustentabilidade, apontadas por Magalhães (1998) e Buarque (2002), e evidenciam a necessidade de participação dos diferentes 
segmentos da sociedade para tratar o saneamento como um direito social integrante de uma política pública com forte ação Estatal, no que tange, inclusive, aos investimentos.

De acordo com Cohn (1995), o mal crônico das políticas públicas e dos programas sociais e uma das causas da falha do planejamento daquelas em países em desenvolvimento são a insuficiência e a instabilidade de recursos financeiros. Em igual sentido, Soares (2004) complementa afirmando que, no caso do gerenciamento dos resíduos sólidos, os entraves verificados, principalmente nos países em desenvolvimento, tornaram-se complexos em razão da quantidade e da diversidade dos materiais descartados, da explosão das áreas urbanas e da restrição das fontes de financiamento.

\section{Investimentos no Setor de Resíduos Sólidos}

Segundo Costa (2010), o fator financeiro sempre foi relevante na evolução do Setor de Saneamento no Brasil, seja por intermédio preferencial do Poder Público, seja do privado. A ampliação da cobertura dos serviços tem demonstrado função direta, entre outros aspectos, na disponibilidade de recursos e na elaboração de planos de engenharia financeira específicos para as necessidades de cada período da história nacional.

A sustentabilidade financeira corresponde a um conjunto de fatores e vai amparar a continuidade dos serviços públicos ao longo do tempo, o que envolve as formas de custeio; os investimentos em infraestrutura, em equipamentos, em inovação tecnológica; além da aplicação de recursos na recuperação de passivos ambientais, como é o caso dos atuais lixões (PricewaterhouseCoopers, 2011).

Apesar da competência para a realização dos serviços públicos relacionados aos resíduos sólidos ser municipal, não menos importante é o papel da União e dos estados no contexto da efetivação da Política Nacional.

Nessa acepção, Cavalcante, Silva e Nascimento (2014) asseguram que o constituinte, ao estabelecer as regras de funcionamento da federação brasileira, ao mesmo tempo em que repassou aos municípios a responsabilidade pelo planejamento e pela gestão de serviços públicos, repassou ao estado membro a responsabilidade de criação de instituições coletivas para o planejamento e a gestão dessas mesmas funções.

Disso decorre a necessidade de que sejam criados mecanismos institucionais que proporcionem a cooperação intergovernamental voltada para a solução de problemas comuns, buscando a conjunção entre os fatores cooperação e coordenação (Mazzali \& Niero, 2012).

No caso da União, a promulgação das Leis № 11.445 (2007) e no 12.305 (2010) destacou seu papel no planejamento do setor, por meio dos Planos Nacionais de Saneamento, coordenado pelo Ministério das Cidades e de Resíduos Sólidos, sob a responsabilidade do Ministério do Meio Ambiente.

O primeiro plano, aprovado por meio do Decreto $\mathrm{n}^{\circ} 8.141$ (2013), contém os objetivos e as metas nacionais e regionais, de curto, médio e longo prazos, para a universalização dos serviços de saneamento básico e o alcance crescente no território nacional, observando a compatibilidade com os demais planos e as políticas públicas da União (Brasil, 2007). O segundo, deve traçar o panorama dos resíduos no país, realizar diagnósticos, definir metas, programas e ações que propiciem o alcance dos objetivos nele estabelecidas, sendo atualizado a cada quatro anos, para coincidir com a elaboração do PPA/federal (Brasil, 2010).

Na versão preliminar do Plano Nacional de Resíduos Sólidos (PNRS), editada em 2011, foi realizado o diagnóstico da situação atual do Brasil, com base no qual foi traçado o cenário para uma gestão adequada do setor sem, contudo, apresentar informações da necessidade de investimentos, tal como previu o Plano Nacional de Saneamento Básico (PLANSAB), cuja versão inicial, de 2011, serviu de base para a elaboração do PPA 2012-2015. No Plano de Saneamento, o total de investimentos previstos para expansão e reposição adequada de resíduos sólidos, no período de 2011 a 2015, por macrorregiões do Brasil, foi de R\$10.921 bilhões, conforme pode ser apresentado na Tabela 1.

Tabela 1 - Necessidade de investimentos em destinação adequada de RSU, segundo Macrorregiões do Brasil, entre o ano base 2011 e os anos de 2015,2020

\begin{tabular}{|c|c|c|c|c|c|c|c|c|c|}
\hline \multirow{3}{*}{$\begin{array}{l}\text { Macrorregião/nature } \\
\text { za dos investimentos }\end{array}$} & \multicolumn{3}{|c|}{ Expansão } & \multicolumn{3}{|c|}{ Reposição } & \multicolumn{3}{|c|}{ Total } \\
\hline & \multicolumn{2}{|c|}{\begin{tabular}{|l|l|l|}
2011 & 2011 \\
\end{tabular}} & \multirow{2}{*}{ 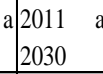 } & \multirow{2}{*}{$\mathrm{a} \mid \begin{array}{ll}2011 & \mathrm{a} \\
2015 & \end{array}$} & \multirow{2}{*}{$\begin{array}{ll}2011 & \mathrm{a} \\
2020 & \\
\end{array}$} & \multirow{2}{*}{$\begin{array}{l}2011 \\
2030 \\
\end{array}$} & \multirow{2}{*}{$\begin{array}{ll}2011 & \mathrm{a} \\
2015 & \\
\end{array}$} & \multirow{2}{*}{$\begin{array}{ll}2011 & \mathrm{a} \\
2020 & \\
\end{array}$} & \multirow{2}{*}{ a $\begin{array}{ll}2011 & a \\
2030 & \end{array}$} \\
\hline & 2015 & 2020 & & & & & & & \\
\hline Norte & 1.209 & 1.264 & 1.345 & 74 & 155 & 332 & 1.283 & 1.419 & 1.677 \\
\hline Nordeste & 3.878 & 3.973 & 4.115 & 260 & 540 & 1.138 & 4.138 & 4.513 & 5.252 \\
\hline Sudeste & 2.542 & 2.614 & 2.720 & 744 & 1.535 & 3.210 & 3.286 & 4.149 & 5.930 \\
\hline Sul & 1.049 & 1.075 & 1.113 & 310 & 636 & 1.319 & 1.359 & 1.710 & 2.431 \\
\hline Centro Oeste & 784 & 816 & 863 & 71 & 149 & 318 & 855 & 965 & 1.181 \\
\hline Total & 9.461 & 9.741 & 10.155 & 1.460 & 3.016 & 6.317 & 10.921 & 12.757 & 16.472 \\
\hline
\end{tabular}

Fonte: Ministério das Cidades. Secretaria Nacional de Saneamento Ambiental. PLANSAB, versão preliminar 2011, Tabela 7.3, 117.Recuperado de http://www.cidades.gov.br/images/stories/ArquivosSNSA

/PlanSaB/Proposta_Plansab_11-08-01.pdf

Conforme a Tabela 1, o total dos investimentos necessários para alcançar, de 2011 a 2015, 100\% da destinação final adequada para os resíduos sólidos urbanos girou em torno de $\mathrm{R} \$ 10,9$ bilhões de reais, distribuídos entre expansão caracterizada pela implantação de soluções de destino final dos RSU nos municípios que não dispunham dessa infraestrutura e pela reposição desta existente. Os recursos para isso seriam provenientes dos agentes federais, via Orçamento Geral da União, e das agências de fomento do governo federal, aporte de agentes internacionais, orçamentos estaduais, municipais e do setor privado (SNSA, 2011).

Vale informar que essa estimativa das necessidades de investimentos na destinação final dos resíduos sólidos urbanos (RSU) foi baseada na atualização do estudo desenvolvido pelo 
MMA e na elaboração de um modelo de estimação de demanda e composição de custos de destinação final adequada, considerando a estrutura lógica e os elementos conceituais do modelo criado para o abastecimento de água potável e o esgotamento sanitário (SNSA, 2011).

Para Costa (2010), os índices de atendimento dos serviços públicos em saneamento básico no Brasil, especialmente no eixo de resíduos sólidos, ainda estão distantes da universalização do acesso pretendido e necessário, já que uma parcela significativa da população não recebe os devidos atendimentos, especialmente nos extratos sociais de mais baixa renda, nas periferias das grandes cidades, nos menores municípios, nas pequenas localidades e na área rural.

Ferraz (2014) considera que as imensas desigualdades de extensão territorial, organização e disponibilidade de recursos, tornam os municípios dependentes da coordenação da União e dos estados, só conseguindo implementar adequadamente as funções correlatas aos resíduos sólidos, por meio da visão regional e da concessão de auxílio financeiro.

É nesse aspecto que os instrumentos de planejamento do governo federal devem trazer mecanismos de estímulo e estratégias de indução para a obtenção da adesão dos demais entes, bem como de transmissão de capitais para que estes consigam cumprir com as responsabilidades impostas pela Lei da Política Nacional de Resíduos Sólidos.

\section{Instrumentos de Planejamento Governamentais e Transferências Voluntárias de Recursos da União aos Municípios \\ Os entes públicos têm como objetivo permanente 0} atendimento das necessidades básicas da população, buscando sempre o bem-estar (Arretche, 2012). Para isso, é necessário implementar práticas diversas que envolvem aspectos financeiros (Costa, 2010). Sua realização, portanto, desenvolve-se por meio da execução orçamentária, caracterizada como a concretização do orçamento, com a consecução de um conjunto ordenado de atividades.

A CF/88 estabelece um sistema orçamentário em que todas as peças (Plano Plurianual - PPA-, Lei de Diretrizes Orçamentárias LDO - e Lei Orçamentária Anual - LOA -) devem estar articuladas, coerentes e harmônicas entre si (Brasil, 1988). A execução orçamentária, compromissada com os objetivos e as estratégias de médio prazo, é fundamental para garantir a eficiência do gasto público (Besen \& Jacobi, 2011).

Nesse sentido, a busca pelo seu aprimoramento deve ser prioridade do governo, exigindo constante aperfeiçoamento do processo orçamentário, em especial no que se refere as conexões com o plano de médio prazo e as respectivas alocações anuais e execução. Para Polo (2009), a necessidade de concebermos o planejamento governamental como um processo mediante o qual se procura definir, claramente, o que fazer e como fazer, visa à utilização racional dos recursos disponíveis para que, com eficiência (adequado uso dos recursos), eficácia (fazer a coisa certa, alcançar os objetivos) e efetividade (impacto do resultado almejado), os objetivos pretendidos possam ser atingidos.

Sob essa perspectiva, o PPA 2012-2015, do governo federal, instituído pela Lei no 12.593 (2012), denominado Plano Mais Brasil, foi estruturado em programas temáticos e de gestão, ambos orientados para a realização dos objetivos estratégicos do Estado. Isso, em linhas gerais, visa dar coerência às ações do governo, em curto e médio prazos, para alcançar os objetivos estratégicos definidos no plano.

A forma de implementação das ações definidas no plano, conforme mostrado na Figura 2, que trata da aplicação de recursos públicos federais, segue um fluxo que inclui aplicações diretas e transferências (CGU, 2012), estando detalhada na Lei Orçamentária Anual e regimentada na Lei de Diretrizes Orçamentárias.

Cabe destacar, preliminarmente, que a descentralização de políticas públicas, com seus respectivos recursos financeiros, da União para os Estados e os Municípios, estão situadas no campo de estudo do Federalismo Fiscal, com previsão em diversos instrumentos legais como é o caso das transferências constitucionais (Brasil, 1988), das transferências legais (Brasil, 2012), das transferências diretas ao cidadão (Brasil, 2000a, 2001, 2004), das transferências diretas ao SUS (Brasil, 2000b) e das transferências voluntárias (Brasil, 2007). É neste último tipo que o presente estudo encontra seu foco, dadas as particularidades que envolvem o assunto.

Figura 2. Aplicação de Recursos Públicos Federais.

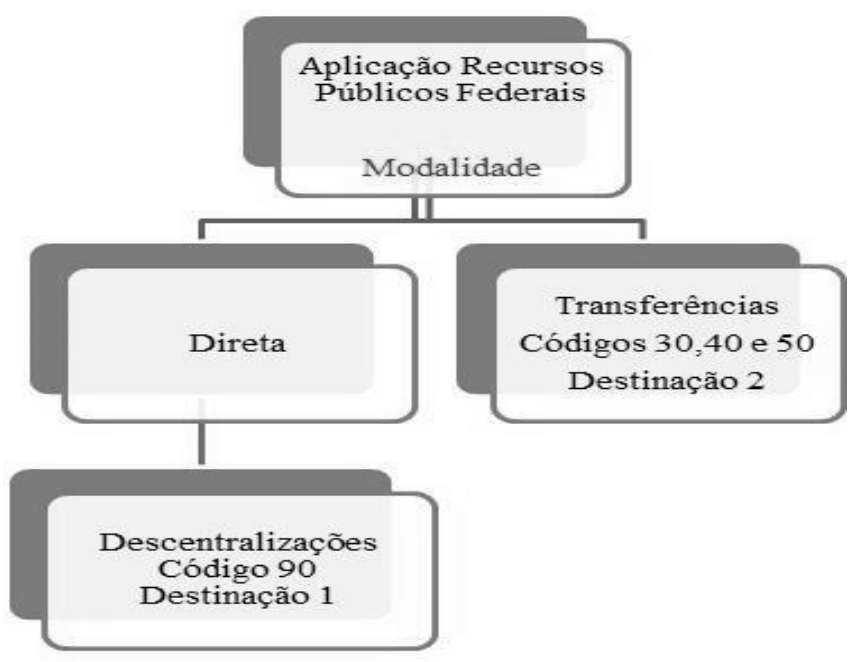

Fonte: Adaptado de Controladoria Geral da União (CGU). (2012). Gestão de Recursos Federais: Manual para os agentes municipais. Brasília, DF: Secretaria Federal de Controle Interno.

Conforme disposto na figura 2, a modalidade de aplicação direta, codificada com o número 90 , refere-se às execuções orçamentárias e financeiras realizadas, a princípio, pelos próprios órgãos ou entidades da Administração Pública Federal (destinação 1), mas também pode ocorrer mediante transferências (destinação 2) para outras unidades, em um processo de descentralização para outra pessoa, física ou jurídica, pública ou privada. Nesse caso, as 
modalidades de aplicação são 30 (Estados), 40 (Municípios) e 50 (Instituições Privadas sem Fins Lucrativos).

A configuração desse arranjo de especificidades de execução consolida as transferências intergovernamentais voluntárias de recursos, caracterizadas, segundo Prado (2007), por decisões discricionárias, para propósitos específicos à realização de um determinado investimento ou à manutenção de padrões mínimos de qualidade em um determinado serviço público prestado, cuja definição legal se encontra disposta no artigo 25 , da Lei Complementar ํㅜ 101(2000):

Para efeito desta Lei Complementar, entende-se por transferência voluntária a entrega de recursos correntes ou de capital a outro ente da Federação, a título de cooperação, auxílio ou assistência financeira, que não decorra de determinação constitucional, legal ou os destinados ao Sistema Único de Saúde (Brasil, 2000).

Martins (2013) evidencia que o acesso aos recursos do Orçamento Geral da União é possibilitado por meio de emendas parlamentares ou por meio da seleção pública de projetos nas áreas setoriais, os quais são operacionalizados, no caso dos municípios, via Convênios ou Contratos de Repasse, em conformidade com o disposto no Decreto no 6.170 (2007).

A modalidade convênio disciplina a transferência de recursos do órgão concedente para o convenente, para executar planos de trabalho, programas, ações ou projetos de interesse recíproco, com duração determinada, em regime de cooperação. Há, portanto, a contrapartida do solicitante, o qual se torna responsável pela utilização dos recursos e posterior prestação de contas (Decreto no 6.170, 2007).

A modalidade contrato de repasse é tipicamente utilizada para regular a transferência de recursos da União para os Estados, o Distrito Federal e para os municípios, com a finalidade de executar programas nacionais por intermédio de instituições ou agências financeiras oficiais, de acordo com o disposto no Decreto $n^{\circ} 6.170$ (2007). Nesse caso, as instituições financeiras, geralmente o Banco do Brasil e a Caixa Econômica Federal, atuam como mandatários da União (Martins, 2010).

No âmbito federal, a Portaria Interministerial CGU/MF/MP no 507 (2011) estabelece os pormenores das transferências voluntárias entre a União e os demais entes, que incluem as exigências demandadas pelos Ministérios da Fazenda, do Planejamento e da Controladoria Geral da União, e elucida todo o trâmite que deve ser observado. Paralelamente a isso, a Lei de Diretrizes Orçamentárias, um dos instrumentos de planejamento do governo federal, regulamenta, todos os anos, o art. 25 da LRF, que trata desse assunto.

A disposição legal dessa possibilidade de descentralização de recursos aos municípios evidencia, na prática, as dimensões políticas e institucional do uso dessas transferências (Gomes,2010; Martins, 2010). Notadamente, Soares (2011), Andrade e Castro (2013), Melo e Soares (2014) destacam que as Transferências Voluntárias da União podem ser utilizadas para fortalecer a capacidade de gastos das prefeituras e a escolha dos destinatários pode ser compreendida com base em três dimensões: a políticopartidária, a redistributiva e a de capacidade técnica.

A dimensão político-partidária envolveria a busca da União por fortalecer suas bases eleitorais e partidárias, privilegiando, no recebimento das transferências, os entes locais que deram maior apoio eleitoral ao presidente em exercício, ou beneficiando os prefeitos dos partidos do presidente ou de sua base aliada. A dimensão redistributiva implica priorizar municípios mais pobres, com menor capacidade de gasto público. Por fim, as exigências para celebrar um convênio requerem uma estrutura de captação de recursos que envolve apresentação de projetos, negociações técnicas e gestão de convênios, além da manutenção regularidade fiscal junto ao Cadastro Auxiliar de Informações para Transferências Voluntárias - CAUC, o que pode favorecer os mais capacitados tecnicamente, e os municípios mais ricos podem ser mais eficientes nesse quesito.

\section{Resultados e Discussão}

Execução das transferências voluntárias do Programa Temático Resíduos Sólidos na perspectiva dos entes municipais

A promulgação da Lei da Política Nacional de Resíduos Sólidos destaca-se no arcabouço jurídico brasileiro como elemento imprescindivel na formalização de metas e indicação de "pontos de chegada" das políticas públicas em resíduos sólidos. Nesse aspecto, o PPA 2012-2015, Lei oㅡ 12.593 (2012), instrumento de planejamento governamental que define diretrizes, objetivos e metas, com o propósito de viabilizar a implementação e a gestão de políticas públicas, inseriu no rol de programas temáticos o de Resíduos Sólidos (2067) para atender, de forma específica, o setor, contendo declarações e metas orientadoras para, em conjunto com as iniciativas, integrarem a programação dos orçamentos anuais.

De certo que a Lei dos Resíduos Sólidos é universal a várias políticas nacionais relacionadas a áreas como mineração, meio ambiente, biodiversidade, recursos hídricos, saúde, mudanças climáticas e industriais, também contempladas em programas temáticos desse PPA, que, mesmo não tendo os resíduos sólidos como foco central, impactam positivamente na implementação da PNRS (Brasil, 2012). O Quadro 1 evidencia os objetivos e as iniciativas vinculados ao Programa Temático Resíduos Sólidos, específico para atender às demandas do setor, coordenado pelo Ministério do Meio Ambiente, objeto deste estudo.

Quadro 1 - Objetivos e Iniciativas do Programa Temático Resíduos Sólidos - PPA2012-2015

\begin{tabular}{|c|c|}
\hline \multicolumn{2}{|c|}{ Programa 2067 - Resíduos Sólidos } \\
\hline Objetivos & Iniciativas \\
\hline $\begin{array}{l}\text { 0319- Ampliar o acesso aos serviços de } \\
\text { manejo de resíduos sólidos urbanos de forma } \\
\text { ambientalmente adequada, induzindo a gestãc } \\
\text { consorciada dos serviços e a inclusão socioeconômice } \\
\text { de catadores de materiais recicláveis. }\end{array}$ & $\begin{array}{l}\text { 0OZE - Apoio e fomento às associações, cooperativas e redes de } \\
\text { cooperação de catadores de materiais recicláveis por meio de formação, } \\
\text { assessoria técnica, infraestrutura e logística em unidades de coleta, triagem, } \\
\text { processamento e comercialização de resíduos. }\end{array}$ \\
\hline
\end{tabular}




\begin{tabular}{|c|c|}
\hline & $\begin{array}{l}\text { 1.2. } 00 Z G \text { - Fortalecimento do poder público para a gestão } \\
\text { regionalizada dos serviços de resíduos sólidos urbanos. } \\
\text { 1.3. } \quad 00 Z \mathrm{H} \text { - Implementação de sistemas de coleta seletiva de resíduos } \\
\text { sólidos urbanos. }\end{array}$ \\
\hline $\begin{array}{l}\text { 0342- Promover a implementação da } \\
\text { Política Nacional de Resíduos Sólidos com ênfase na } \\
\text { reestruturação das cadeias produtivas, na integração } \\
\text { das associações, cooperativas e redes de cooperação } \\
\text { de catadores, na estruturação do planejamento do } \\
\text { setor, no gerenciamento de áreas contaminadas e na } \\
\text { inovação tecnológica respeitando as peculiaridades } \\
\text { regionais. }\end{array}$ & 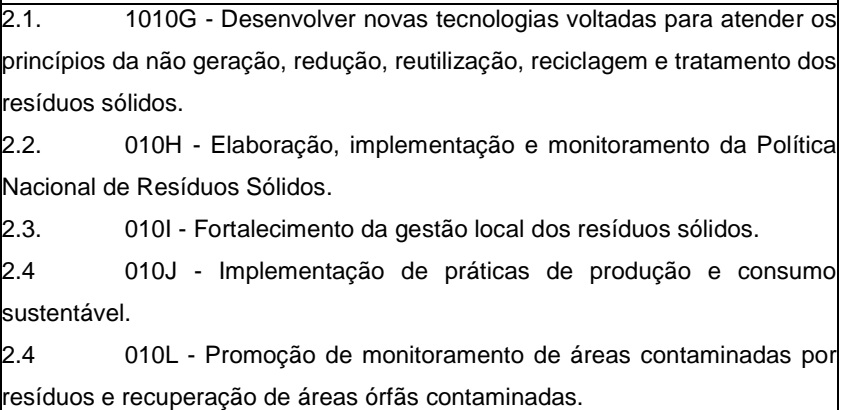 \\
\hline
\end{tabular}

Fonte: Secretaria do Orçamento Federal. Ministério do Planejamento Orçamento
http://www.planejamento.gov.br/secretarias/upload/arquivo/spi-1/ppa-1/2012/151117_anexo_i_2012-2015.pdf

No desdobramento das ações do programa nos orçamentos anuais, programação quantitativa, foi possível identificar a previsão e a autorização de recursos para execução centralizada, na esfera federal, e descentralizada aos demais entes subnacionais e a outras entidades visando ao fomento das políticas do setor vinculadas a implementação da Política Nacional de Resíduos Sólidos. O Gráfico 1, que congrega informações do Siga Brasil (2015), apresenta o detalhamento da destinação dos recursos constante no OGU, por modalidade de aplicação, nos exercícios 2012-2015.

Gráfico 1. Destinação dos Recursos por modalidade de Aplicação no Programa Federal de Resíduos Sólidos, período 2012-2015.

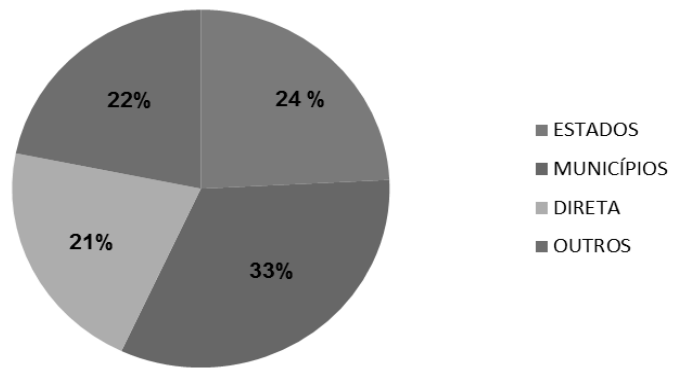

Fonte: Adaptado de SIGA Brasil. Senado Federal. Portal Orçamento. (2015). Recuperado de https://www12.senado.leg.br/orcamento/sigabrasil

A dotação orçamentária autorizada pelo Congresso Nacional no período foi de aproximadamente 530 milhões de reais para atendimento da PNRS. Desse total, 33\% foram destinados para a modalidade transferências aos municípios; seguido pelos estados, com $24 \%$, depois $21 \%$, para a modalidade aplicação direta, executada pelo próprio governo federal, e $22 \%$ destinados para outras modalidades, que incluem entidades sem fins lucrativos e consórcios públicos. Conforme representado, a modalidade transferências aos municípios teve o maior percentual de participação na dotação global autorizada para o programa.

Segundo o Ministério do Meio Ambiente, essa destinação decorreu da necessidade de dar suporte aos municípios na estruturação do setor, diante da obrigação de cumprir a Lei da PNRS (Araújo, 2014). No estudo conduzido por Moutinho (2015) acerca dessas transferências, há forte evidência de que o volume dos repasses tem crescido substancialmente nas últimas décadas, apesar de se tratar de recurso discricionário, em razão de o ente municipal exercer função primordial nas demandas locais (saúde, educação, saneamento básico etc) por estar mais próximo dos cidadãos.

Os resultados da execução do Programa Resíduos Sólidos em relação aos recursos descentralizados, tomando por base os valores autorizados anualmente pelo legislativo federal, Tabela 2 , indicam a existência de prolongamento excessivo no fluxo percorrido para o ingresso efetivo dos recursos nos cofres dos municípios, dada a necessidade de cumprimento das etapas de execução da despesa pública - empenho, liquidação, pagamento-, considerando que cada uma dessas fases exige o cumprimento de requisitos pré- estabelecidos, conforme preceitua a Lei ํo 4.320 (1964).

Tabela 2 - Execução Orçamentária e Financeira do Programa na modalidade Transferências aos Municípios, nos anos $2012-2015$

Período/LOA R $\$$ /Autorizado R R/Empenhado R R/Liquidado R R/Pago no ano R


2013

49.348 .178

4.406 .773

0,00

0,00

0,00

\begin{tabular}{rr|crrr}
2014 & 4.211 .501 & 4.082 .138 & 623.427 & 623.427 & 210.800 \\
\hline 2015 & 25.305 .348 & 670.800 & 210.800 & 2.329 .685 \\
\hline Total & $\mathbf{1 7 3 . 2 4 2 . 9 9 1}$ & $\mathbf{3 2 . 4 4 8 . 8 9 8}$ & $\mathbf{2 . 4 6 2 . 1 9 1}$ & $\mathbf{2 . 4 6 2 . 1 9 1}$ \\
\hline
\end{tabular}

Fonte: Adaptado de Siga Brasil. Senado Federal. Portal Orçamento. (2015). Recuperado de https://www12.senado.leg.br/orcamento/sigabrasil

Do montante autorizado no período analisado, Gráfico 2, valor acumulado de 173 milhões de reais, somente 32 milhões foram empenhados $(18,73 \%)$, ou seja, atingiram o primeiro estágio da despesa pública, que vincula os recursos orçamentários do tesouro ao gasto correspondente. Na sequência, estão a liquidação, que reconhece o direito do convenente, e o depósito financeiro, também chamado pagamento, que representa a efetivação do repasse dos recursos (Brasil, 1964).

Gráfico 2 - Valores Autorizados X Realizados nas Transferências do Programa Resíduos Sólidos aos Municípios 2012-2015

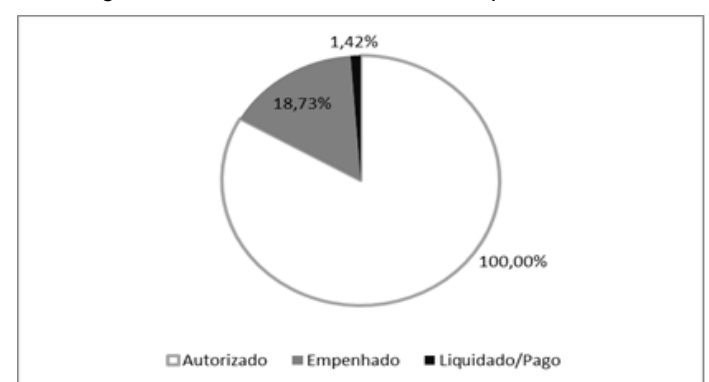

Fonte: Adaptado de Siga Brasil. Senado Federal. Portal Orçamento. (2015). Recuperado de https://www12.senado.leg.br/orcamento/sigabrasil.

Desse valor autorizado, aproximadamente 2,5 milhões $(1,42 \%)$ foram efetivamente liberados dentro dos exercícios financeiros correspondentes. Vale ressaltar que é por meio da disponibilidade em caixa que o município beneficiário da transferência voluntária tem a possibilidade de materializar a ação do objeto pactuado. Em relação à execução das etapas das despesas públicas, há que se destacar, ainda, que os valores empenhados até 31 de dezembro do ano de referência, liquidadas ou não, são inscritas em Restos a Pagar (RP), para a realização em exercícios posteriores (Brasil, 1964).

A excessiva concentração de recursos em RP, de acordo com os órgãos de controle da administração pública, tende acarretar impacto negativo na implementação das políticas públicas, já que a efetivação da ação é dilatada (TCU,2012). O volume de recursos inscritos em RP totalizou 29,9 milhões (despesa empenhada, deduzida a liquidada) e apenas 7,4 milhões (24,79\%) foram liberados (pagos) nos últimos anos do quadriênio analisado, indicando instrumentos assinados entre a União e os municípios que se estenderam para outros anos.

Com base nessa constatação, ficam evidenciadas dificuldades na captação e na execução das transferências pelos entes municipais, em que pese a existência de regulamentação federal e a disponibilidade de recursos pela União, ainda que de forma incipiente, se comparadas às necessidades de investimentos do setor. Se de um lado os gestores alegam a falta de recursos para aplicar em ações do setor; de outro, encontram dificuldades para obter tais recursos.

Ao tratar dos arranjos políticos para políticas públicas, Keppke (2015) sustenta que as últimas gestões têm sido prolíferas na edição de políticas nacionais, muitas delas financiadas por programas e por transferências voluntárias do governo federal, com vistas a induzir as instâncias federativos a implementá-las. Mas é instigante observar que as políticas com responsabilidade compartilhada, com determinação legal de prazos de cumprimento e com oferta relativamente abundante de incentivos financeiros não garantam a implementação "per se". Para exemplificar, a autora cita a Política Nacional de Resíduos Sólidos.

O paradoxo é explicado por fatores políticos e administrativos identificados entre as unidades federadas e dentro delas, evidenciando a necessidade de as políticas nacionais compartilhadas, como no caso do Setor de Resíduos Sólidos, operarem com base na combinação satisfatória de descentralização de recursos e de responsabilidades, articulação técnica e política (Keppke, 2015; Alcântara, Silva \& Pereira, 2016).

Para o TCU (2012), órgão que acompanha e monitora os instrumentos de planejamento governamentais da União, a realização de transferências voluntárias (convênios e contratos de repasse) na PNRS para os entes subnacionais deve ser condicionada à apresentação de projetos vinculados ao plano municipal ou intermunicipal de gestão integrada de resíduos sólidos, visto que a falta desses instrumentos tem contribuído para a insustentabilidade de empreendimentos objeto de pactuação de recursos, ocasionando desperdícios e baixa efetividade na execução do programa.

A Lei no 12.305 (2010) é quem estabelece o Plano Municipal de Gestão Integrada como condição necessária para o Distrito Federal e os municípios terem acesso aos recursos da União, ou para serem beneficiados por incentivos ou financiamentos de entidades federais de crédito ou fomento, priorizando aqueles que optarem por soluções consorciadas, bem como os que implantarem a coleta seletiva, com a participação dos catadores de materiais reutilizáveis e recicláveis. Contudo muitas cidades brasileiras ainda não dispõem desses instrumentos de planejamento. De acordo com dados da Pesquisa Básica Municipal, do Instituto Brasileiro de Geografia e Estatística (IBGE) (2013), apenas 1/3 dos municípios brasileiros, $33,5 \%$ da amostra do total de 1.865 , declararam possuílo.

As exigências da Lei de Responsabilidade Fiscal (LRF), no tocante à regularidade no Cadastro Único de Transferências Voluntárias (CAUC), têm sido destacadas também como fator impeditivo na obtenção dos recursos pelos municípios. O CAUC é 
um cadastro mantido e coordenado pela Secretaria do Tesouro Nacional (STN) e contém informações de vários órgãos da Administração Federal. Em referência à regularidade fiscal de tributos e contribuições federais, à Dívida Ativa da União, às Contribuições Previdenciárias e ao FGTS, além da regularidade em relação à Adimplência Financeira em Empréstimos e Financiamentos, concedidos pela União, perante o Poder Público Federal-CADIN, e ao adimplemento na Prestação de Contas de outros Convênios. Como muitos municípios não cumprem essas exigências, eles deixam de pactuar recursos. De acordo com o monitoramento realizado pela Confederação Nacional dos Municípios (CNM), pelo menos $80 \%$ destes possuíam restrições nesse cadastro, entre os anos de 2013 e 2015.

Martins (2013), no estudo intitulado Programa de Acesso aos Recursos de Saneamento, observa que o associativismo municipal, tratado na Lei Federal dos Consórcios Públicos, Lei nº 11.107 (2005), cuja utilização na prestação de serviços na área de resíduos sólidos é passível de elevar a eficiência na prestação dos serviços, reduzindo os custos, ainda não é prática contumaz em todo o país. Os entes que se enquadram nessa sistemática aumentam as possibilidades de cumprir adequadamente as etapas de obtenção e execução das transferências.

Essa forma de associativismo, segundo o autor, tem efetivadose entre os municípios localizados nas Regiões Sudeste e Sul, enquanto nas demais regiões ainda é incipiente, aspecto que pode ser observado na distribuição territorial dos recursos do programa (Gráfico 3) em que grande parte das transferências, efetivamente realizadas, teve como destino municípios situados na Região Sudeste do Brasil.

Gráfico 3. Regiões beneficiárias de recursos do Programa Resíduos

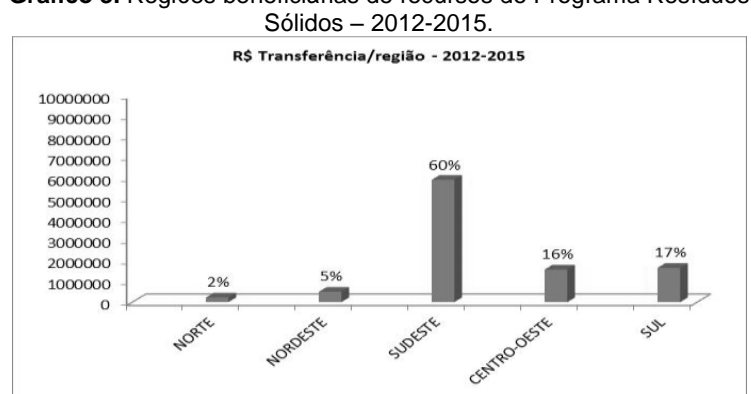

Fonte: Adaptado de SIGA Brasil. Senado Federal. Portal Orçamento. (2015). Recuperado de https://www12.senado.leg.br/orcamento/sigabrasil.

Para Andrade e Castro (2013), o gestor do município deve levar em conta que há necessidade de um planejamento amplo, que envolve desde a programação de contrapartidas de recursos, documentação regular, aplicação dos recursos condizentes com os planos de trabalho aprovados até a prestação de contas tempestiva, além de dispor de mecanismos adequados para promover a boa gestão dos recursos, já que descentralização financeira, por parte do governo federal, exige coordenação, monitoramento e controle do ciclo das transferências voluntárias, desde a celebração do instrumento (convênio ou contrato de repasse) até a prestação de contas final.

A aderência ou não dos municípios às políticas públicas federais depende de sua capacidade para implementá-las, pois a descentralização e as redes de atores que operam nos processos decisórios têm impacto sobre as formas de fornecimento dos bens públicos (Anastasia, 2004; Arretche, 2012).

\section{Considerações Finais}

A temática dos resíduos sólidos é uma preocupação evidente na atualidade, pois o despejo irregular e o mau tratamento comprometem a qualidade de vida da população, encadeando, com isso, uma série de demandas para o Estado, principalmente na área da saúde. Portanto, a busca de soluções para esse problema requer a articulação entre as diversas políticas públicas, já que o tema não pode ser tratado de forma isolada.

Nessas circunstâncias, a necessidade de esforços institucionais dos três níveis do governo, União, Estados e Municípios, para colocar em prática as diretrizes da Política Nacional de Resíduos Sólidos foi evidenciada. Para tanto, é de grande importância a elaboração e o cumprimento dos instrumentos de planejamento do setor, já que neles são definidas as soluções e as metas a serem adotadas, bem como previstas soluções compartilhadas, tanto para regulação quanto para prestação dos serviços, os quais requerem investimentos vultosos.

A descentralização de políticas públicas com seus respectivos recursos financeiros da União para os municípios está prevista em diversos instrumentos legais, como é o caso das transferências voluntárias (Brasil, 2007). Em uma situação de ajuste fiscal, em que os entes locais têm baixa capacidade de endividamento e devem priorizar gastos sociais, com vinculação crescente das receitas nessas áreas, sobra pouca margem para os municípios ampliarem seus gastos com outras políticas públicas, e as transferências voluntárias da União acabam se tornando recursos atraentes e cobiçados (Arretche, 2012, Prado,2007; Soares, 2011).

Esse breve levantamento efetuado em torno das transferências voluntárias para as políticas públicas do Setor de Resíduos Sólidos tomando por base o programa temático específico do PPA federal 2012-2015 não teve a pretensão de esgotar o tema acerca da descentralização desses recursos para os entes municipais, mas trazer para a discussão o que eles representam na concretização da Política Nacional de Resíduos Sólidos, de forma a contribuir para 
melhorar a gestão do sistema e, consequentemente, a qualidade de vida da população.

O teor predominantemente orçamentário e financeiro em torno da análise depreendida é ponto de destaque, na medida em que são citadas pelos entes municipais como fator que impossibilita a concretização da PNRS. Do mesmo modo, os mecanismos que possibilitam o acesso a esses recursos tangenciam a discussão, dado que se destaca como fator que interfere na operacionalização das transferências. Conforme demonstrado, o Programa Temático Resíduos Sólidos, coordenado pelo Ministério do Meio Ambiente, com recursos autorizados para execução dessa política em âmbito nacional, destinou parcelas desses recursos para a execução, de forma descentralizada, aos demais entes federativos, via transferências voluntárias. Aos municípios, coube 0 maior percentual de destinação, em torno de $33 \%$ do montante autorizado no quadriênio.

Acrescente-se que, apesar de esse volume de recursos ter sido incipiente, se consideradas as projeções do Plano Nacional de Saneamento Básico para universalização do acesso, ao examinar a execução orçamentária e financeira do Programa Resíduos Sólidos, na perspectiva dos entes municipais, foi constatado que o acesso efetivo aos recursos apresentou um percentual de realização muito baixo, em torno de 1,42\%, nos exercícios financeiros 2012 a 2015, em relação ao valor autorizado. Ademais, foi registrado um volume significativo de restos a pagar, sendo pagos até o último período de vigência do PPA federal 2012-2015, aproximadamente, $25 \%$ do valor, sinalizando um programa com dificuldades de execução.

Entre os fatores que interferem nesse cenário, estão as condicionantes de cunho político e técnico, incluindo a ausência dos planos municipais de resíduos sólidos, exigência da Lei n 12.305 (2010), restrições no Cadastro Único Transferências Voluntárias, do governo federal, e incipiente associativismo entre os entes municipais. Citem-se, ainda, limitações técnicas no que se refere à elaboração de projetos para captação de recursos, diante das particularidades e da complexidade do setor.

Pode-se dizer que ocorreu mudança no ordenamento jurídico nacional, introduzida, sobretudo, pelas Leis de Saneamento Básico e da Política de Resíduos Sólidos. Portanto, do ponto de vista normativo, a PNRS encontra-se bem aparelhada, considerando que, por muito tempo, a falta de regulamentação do setor foi utilizada para justificar a falta de estrutura nos municípios brasileiros. Mas é preciso que, na prática, passem a integrar as ações das políticas públicas, traduzida efetividade da gestão dos recursos orçamentários e financeiros, de forma que possa, efetivamente, contribuir para o cumprimento das diretrizes da PNRS, diminuindo impacto ambiental e melhorando as condições de saúde da população nos municípios brasileiros.

\section{Referências}

Alcântara, V. C., Silva, E. A. F., \& Pereira, J. R. (2016). Governança e Esfera Pública Sobre Resíduos Sólidos Urbanos no Âmbito Municipal. Revista Administração Pública e Gestão Social, v. 8, no 3 .
Anastasia, F. Federação e Relações Intergovernamentais. (2004). In: Avelar, A. L \& Cintra, A. O (Org.). Sistema político brasileiro: uma introdução (pp. 185203). São Paulo: Fundação UNESP.

Andrade, B. R. C. de. \& Castro, M. H. G. de. (2013, outubro) A Importância da implementação de um órgão de projetos e Convênios para captação de recursos para os municípios brasileiros. Congresso Internacional Governo, Gestão e Profissionalização em âmbito local frente aos grandes desafios de nosso tempo. Belo Horizonte, MG, Brasil, 4.

Araújo, P. (2014). Política de Resíduos Sólidos apresenta resultados em 4 anos. Recuperado de<http://www.mma.gov.br/informma/item/10272 pol\%C3\% ADtica-de-res\%C3\%ADduos-s\%C3\%B3lidos-apresentaresultados-em-4-anos. Acesso em: 10 mar. 2016.

Arretche, M. T. S. (2012). Financiamento federal e gestão de políticas sociais o difícil equilíbrio entre regulação, responsabilidade e autonomia, 8 (2), 331 345.

Associação Brasileira de Limpeza Pública (ABRELPE). (2014). Panorama dos Resíduos Sólidos no Brasil. Recuperado de http:// www.abrelpe.org.br.

Buarque, S. C. (2002). Construindo o Desenvolvimento Local Sustentável. Rio de Janeiro: Garamond.

Carvalho, A. R.; Oliveira, M. V. C. (2011). Princípios Básicos do Saneamento do Meio (10a ed.). São Paulo: SENAC.

Confederação Nacional dos Municípios (CNM). (2015). Recuperado de http://www.cnm.org.br

Cavalcante, J. P. S.; SILVA, C. L.; Nascimento, D. E. (2014). Cooperação Intergovernamental na região metropolitana de Curitiba: O caso do transporte coletivo(pp.1-22). II Semana de Pós-Graduação em Ciência Política. São Paulo, SP, Brasil, 2.

Cohn, A. (1995). Políticas sociais e pobreza no Brasil.Planejamento e Políticas Públicas, (12), 1-17.

Constituição da República Federativa do Brasil. Brasília, 1988. DOU de 5.10 .1988 .

Controladoria Geral da União (CGU). (2012). Gestão de Recursos Federais: Manual para os agentes municipais. Brasília, DF: Secretaria Federal de Controle Interno.

Controladoria Geral da União (CGU). (2014). Portal da Transparência. Recuperado de http://www.portaltransparencia.gov.br.

Costa, B. S. (2010). Universalização do Saneamento Básico: utopia ou realidade. A efetivação do capital social na política pública do saneamento básico. (Tese de Doutorado em Engenharia Ambiental). Universidade Federal de Santa Catarina, Florianópolis, SC, Brasil.

Decreto no 6.170 de 25 de julho de 2007. (2007). Dispõe sobre as normas relativas às transferências de recursos da União mediante convênios e contratos de repasse. Brasília, DF: Casa civil. Recuperado de http://www.planalto.gov.br/ccivil_03/_ato2007-2010/2007/decreto/d6170.htm. Decreto $n^{\circ} 7.217$ de 21 de junho de 2010.(2010). Regulamenta a Lei $\mathrm{n}^{\circ} 11.445$, de 5 de janeiro de 2007, que estabelece diretrizes nacionais para - saneamento básico. Brasília, DF: Casa Civil. Recuperado de http://www.planalto.gov.br/ccivil_03/_ato2007-

2010/2010/decreto/D7217.htm.

Decreto $n^{\circ}$ 7.404, de 23 de dezembro de 2010. (2010). Regulamenta a Le $\mathrm{n}^{\circ} 12.305$, de 2 de agosto de 2010, que institui a Política Nacional de Resíduos Sólidos. Brasília, DF: Casa Civil. Recuperado de http://www.planalto.gov.br/ccivil_03/_ato2007-2010/2010/decreto/d7404.htm.

Decreto $n^{\circ}$ 8.141, de 20 de novembro de 2013. (2013). Dispõe sobre o Plano Nacional de Saneamento Básico - PNSB, institui o Grupo de Trabalho Interinstitucional de Acompanhamento da Implementação do PNSB e dá outras providências. Brasília, 2013

Ferraz, Á. B. (2014). A articulação federativa para a viabilização da Política Nacional de Resíduos Sólidos no Brasil (Dissertação de mestrado). Universidade São Paulo, São Paulo, SP, Brasil.

Garcia, A. F. M.; Flores, G. № (2015). Possibilidade jurídica da gestão integrada de resíduos sólidos urbanos através de consórcios públicos. Revista Eletrônica Direito e Política5(1). Recuperado de www.univali.br/direitoepolitica.

Gil, A. C. (2002). Como Elaborar Projetos de Pesquisa. São Paulo: Atlas.

Gomes, E.C.S. (2007) Fundamentos das transferências intergovernamentais. Revista do Tribunal de Contas da União, v. 39, no 110, p. 28- 40. Recuperado de <http://lx-frb-bwp.srv.trt02.gov.br/siabiwebphp/Telas/TitulosDetalhe.php?cod=102529\&pag=108>. Acesso em: 22. Abr. 2015

Heller, L. (2005). O papel do Governo Federal: o papel da União na política de saneamento básico, entre o que se deve e o que pode esperar Livro 1 pp. 93-103). Brasília.

Instituto Brasileiro de Geografia e Estatística. (2014). Pesquisa Básica dos Municípios.

Recuperado

http://www.ibge.gov.br/home/estatistica/economia/perfilmunic/2013/

Instituto Tratta Brasil. (2014). Portal Eletrônico Portal Eletrônico Portal Eletrônico. Recuperado de http://www.tratabrasil.org.br.

Jacobi, P. R; Besen, G. R. (2011). Gestão de Resíduos Sólidos em São Paulo: desafios da sustentabilidade. Estudos Avançados, 25, (71),135-158.

Keppke, R. S. Capacitação: catalisador de arranjos federativos para políticas públicas. In: Congresso de Gestão Pública. Brasília, DF, Brasil, 8. 
Lei no 4.320 de 17 de março de 1964. (1964). Institui normas gerais de direito financeiro para elaboração e controle dos orçamentos e balanços da União, dos Estados, dos Municípios e do Distrito Federal. Brasília, DF: Casa Civil e. Recuperado de http://www.planalto.gov.br/ccivil_03/leis/LCP/Lcp101.htm.

Lei Complementar no 101 de 05 de maio de 2000. (2000). Estabelece Normas de Finanças Públicas voltadas para a Responsabilidade Fiscal e dá outras providências. Recuperado de http://www.planalto.gov.br/ccivil_03/L4320.htm.

Lei no 11.107, de 6 de abril de 2005. (2005). Dispõe sobre normas gerais de contratação de consórcios públicos e dá outras providências. Recuperado de http://www.planalto.gov.br/ccivil_03/_ato2004-2006/2005/lei/l11107.htm.

Acesso em: 20. abr. 2016.

Lei $n^{\circ}$ 11.445, de 05 de janeiro de 2007. (2007) Estabelece diretrizes nacionais para o saneamento básico. Brasília, DF: Casa Civil. Recuperado de http://www.planalto.gov.br/ccivil_03/_ato2007-2010/2007/lei/11445.htm.

Lei no 12.305 de 02 de agosto de 2010. (2010). Institui a Política Nacional de Resíduos Sólidos. Brasília, DF: Casa Civil. Recuperado de http://www.planalto.gov.br/ccivil_03/_ato2007-2010/2010/lei//12305.htm.

Lei no 12.593 de 18 de janeiro de 2012. (2012). Institui o Plano Plurianual da União para o período 2012-2015. Brasília, DF: Casa Civil. Recuperado de http://www.planalto.gov.br/legislação.

Logarezzi, A. (2004). Contribuições conceituais para o gerenciamento de resíduos sólidos e ações de Educação Ambiental. In: LEAL, A. C. et al. Resíduos sólidos no Pontal do Paranapanema. Presidente Prudente - SP: Viena.

Magalhães, A. (1998). Um estudo de desenvolvimento sustentável no nordeste semi-árido. In: CAVALCANTI, C. (Org.). Desenvolvimento e natureza - estudos para uma sociedade sustentável. Recife: Fundaj; São Paulo: Cortez. p. 417-429.

Martins, C. H. B. (2006). Trabalhadores na reciclagem e na gestão de resíduos sólidos na Região Metropolitana de Porto Alegre: dinâmicas econômicas, socioambientais e políticas. In: JACOBI, P. (Org.). Gestão compartilhada dos resíduos sólidos no Brasil: inovação com inclusão social. São Paulo: Annablume.

Martins, R. (2013). Programa de Acesso aos Recursos de Saneamento. Brasília, DF: ENAP.

Martins, T. W. (2010). Transferências Voluntárias no Brasil: critérios para distribuição de recursos para os municípios e estados brasileiros. 2010. Monografia -(Especialização em Orçamento Público). Instituto Serzedello Correa, Brasília, DF.

Massukado, L. M. (2004). Sistema de apoio à decisão: Avaliação de Cenários de Gestão Integrada de Resíduos Sólidos Urbanos Domiciliares (Dissertação de Mestrado). Universidade São Carlos, São Paulo, SP, Brasil.

Mazzali, L.; Niero, J.C.C. (2012, maio/agosto). Gestão das relações intermunicipais. Revista Metropolitana de Sustentabilidade, 2, 2, pp. 33-47.

Melo, P. C. S. (2012). Monitoramento e Avaliação na Administração Pública Federal: Os desafios do PPA 2012/2015 (Monografia de Especialização). Instituto Serzedelo Correa, Brasília, DF, Brasil.
Melo, B.G.;Soares, M. M.(2016). Condicionantes políticos e técnicos das transferências voluntárias da União aos municípios brasileiros. Revista de Administração Pública, v. 50, no 4, p. 539-562.

Ministério das Cidades. Secretaria Nacional de Saneamento Ambiental.PLANSAB, versão preliminar 2011. (2011). Recuperado de http://www.cidades.gov.br/imagens/stories/ArquivoSNSA.

Ministério do Planejamento, Orçamento e Gestão. (2015). Portal dos Convênios. Recuperado de http://www.convenios.gov.br/portal.

Moutinho, J.A. (2016). Transferências voluntárias da União para municípios brasileiros: mapeamento do cenário nacional. Revista Administração Pública e Gestão Social, v. 50, no 1.

Paiva, Cícero Otávio de Lima. (2012) Ordenamento Jurídico Brasileiro e a evolução no tratamento de resíduos sólidos. Revista $C A A P, 18,1$, pp.135158.

Phillipi Jr., A; Aguiar, A. O. (2005). Resíduos Sólidos: Características e Gerenciamento. In:Phillipi Jr.,A. (Org.). Saneamento, Saúde e Meio Ambiente: Fundamentos para um desenvolvimento sustentável. São Paulo:Manole.

POLO. J.C. (2009). Planejamento e Orçamento no setor público brasileiro (Cap. 2, pp. 7-22). São Paulo: Fundap.

Portaria Interministerial MPOG/MF/CGU no 507, de 24 de novembro de 2011. (2011). Estabelece normas para execução do disposto no Decreto no 6.170 , de 25 de julho de 2007, que dispõe sobre as normas relativas às transferências de recursos da União mediante convênios e contratos de repasse. Brasília, DF: MPOG.

Prado, S. (2007). Distribuição intergovernamental de recursos na Federação brasileira. In: Rezende, F. \& Oliveira, F. A. (Org.). Descentralização e federalismo fiscal no Brasil: desafios da reforma tributária. Rio de Janeiro: Konrad Adenauer Stiftung.

Pricewaterhousecoopers Serviços Profissionais Ltda - PwC. Guia de Orientação para Adequação dos Municípios à Política Nacional de Resíduos Sólidos (PNRS). São Paulo, 2011. 138 p.

Santos, E. A. V. (2011). O Confronto entre o Planejamento Governamental e o PPA. In: Cardoso Júnior, J. C. (Org.).Diálogos para o Desenvolvimento. A reinvenção do planejamento governamental no Brasil. (pp. 307-336). Brasília: Instituto de Pesquisa Econômica Aplicada (IPEA).

SIGA Brasil. Senado Federal Portal Orçamento. (2015). Recuperado de http://www9.senado.gov.br/portal/page/portal/orcamento_senado

Sistema Nacional de Informação sobre Saneamento (SNIS). Portal Eletrônico. Brasília, DF, 2013. Recuperado de http://www.snis.gov.br.

Soares, № M. B. (2004). Gestão e gerenciamento dos resíduos sólidos domiciliares no município de fortaleza-CE (Dissertação de Mestrado). Universidade Federal de Fortaleza, Fortaleza, Ceará, Brasil.

Tribunal de Contas da União. (2008). Convênios e outros repasse/Tribunal de Contas da União. 2. ed. Brasília, DF: Secretaria - Geral de Controle Externo. 